\title{
Qualidade da educação universitária: isomorfismo, diversidade e eqüidade
}

Marília Costa Morosini ${ }^{1}$

MOROSINI, M. C. The quality of higher education: isomorphism, diversity and fairness, Interface _ Comunic, Saúde, Educ, v.5, n.9, p.89-102, 2001.

The international trends that emerged in the age of knowledge, intensified as a result of internationalization and the development of new communication technologies, have markedly disseminated amongst us (a country historically characterized by State control of higher education) the era of quality. This paper examines different concepts and strategies of quality in higher education, which resulted from international experiences. Among the main concepts that of quality stands out, synonymous with isomorphism, reflecting itself in the form of standardized institutional evaluation and employability; quality, synonymous with respect for specificities; and quality, synonymous with fairness. Because of the lack of bibliography approaching the theme from a holistic point of view, this paper, rather than presenting propositions, raises issues as regards the relation of educational innovation and quality, and the unity of the concept of quality and Brazilian reality.

KEYWORDS: Quality; organizational innovation; university; institutional evaluation; higher education.

As tendências internacionais trazidas pela idade do conhecimento, acirradas pela internacionalização e pelo desenvolvimento de novas tecnologias de comunicação, têm disseminado, marcadamente, entre nós, país caracterizado historicamente pela controle do Estado sobre a educação superior, a era da qualidade. Este trabalho examina diferentes concepções e estratégias de qualidade universitária, advindas de experiências internacionais. Entre os principais conceitos destacam-se o de qualidade, sinônimo de isomorfismo, refletindo-se como avaliação institucional estandartizada e empregabilidade; qualidade, sinônimo de respeito às especificidades; e qualidade, sinônimo de equidade. Pela escassez de bibliografia quanto a uma visão holística do tema, este trabalho, mais do que apresentar propostas, levanta questionamentos quanto à relação entre qualidade $e$ inovação educativa e unicidade do conceito de qualidade e a realidade brasileira.

PALAVRAS-CHAVE: Qualidade; inovação organizacional; universidade; avaliação institucional, educação superior.

1Professora do Programa de Pós-Graduação em Educação, Universidade Luterana Brasileira/ULBRA; Universidade Federal do Rio Grande do Sul/UFRGS; pesquisadora do CNPq. <morosini@pro.via-rs.com.br> 
Falar em qualidade é repisar um modismo dos últimos anos. Em todos os cantos da Educação, principalmente da Educação Superior, em todos os níveis tudo se faz em nome da qualidade. Qualidade é ser moderno, é ser inovador. Mas o entendimento do conceito de qualidade é o mesmo para todos? Certamente não. Alguns enquadram qualidade na concepção de isomorfismo, articulada à idéia da empregabilidade e à lógica de mercado. Outros a entendem como respeito à diversidade e para outros, ainda, a qualidade vem imbricada ao conceito de eqüidade. Tais conceitos são muito mais categorias aproximativas do que tipos ideais e as práticas de avaliação universitária, muitas vezes, combinam as características de obediência à padronização, respeito às especificidades e/ou busca de eqüidade.

Este texto pretende examinar diferentes concepções de qualidade, buscando relacioná-las com estratégias advindas de experiências internacionais, considerando que estas têm sido encarados como modelos para a realidade brasileira. Não se objetiva aqui levantar um estado da arte do termo qualidade em Educação Superior, mas identificar grandes conceitos categoriais que agregam significados similares, aqui não identificados a partir de uma metodologia rigorosa de varrição do produzido num tempo, local e fonte específicos. A análise adveio, muito mais, da consulta à biblioteca virtual Universitas (Anped, 2001), que abarca periódicos publicados no país desde 1968 (ano da reforma universitária) e informações nacionais e internacionais sobre produções da área.

\section{Qualidade, sinônimo de avaliação}

Teorias organizacionais de administração universitária concebem a qualidade como um conjunto de fases do tradicional ciclo de qualidade: planejamento, ação, avaliação e promoção. Entretanto, no final da década de oitenta e durante a década de noventa, foi registrado o desvirtuamento da concepção de qualidade, como um conjunto de fases, para a predominância da fase da avaliação. São identificadas, no tempo e no espaço, diversas concepções e práticas de avaliação: a) desde aquelas avaliações dirigidas por princípios financeiros até aquelas dirigidas pelo conceito central de qualidade; b) desde as baseadas em metodologias que objetivavam simplesmente a avaliação até aquelas que objetivavam a avaliação para credenciamento; c) desde as que consideravam programas de estudos até aquelas que avaliavam instituições.

A grande maioria das instituições desenvolve a avaliação universitária por pressão direta e/ou indireta de órgãos governamentais. Qualidade vem amarrada com avaliação, com padrões, com coleta exaustiva de dados etc.. que definem os bons serviços prestados e a garantia de êxito institucional. Inúmeras tentativas de medir a qualidade são detectadas, predominando a identificação de estágios de auto-avaliação, avaliação externa e relatórios analíticos (Van Vught, 1993). Publicações, revistas e seminários sobre o assunto também são desenvolvidos. Políticas Públicas ${ }^{2}$ de sobrevivência do ente universitário, de reconhecimento, credenciamento e recredenciamento da organização são determinadas. Decorrente daí são instituídas comissões nas organizações universitárias para a avaliação institucional que, na grande

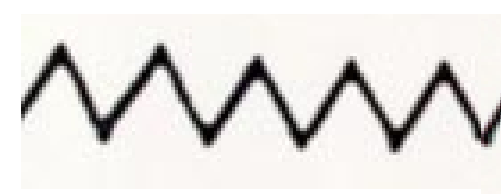

${ }^{2}$ No caso brasileiro, mais recentemente (1996/98) o MEC

abarcou o Programa de Avaliação Institucional das Universidades Brasileiras (PAIUB), movimento relativamente autônomo liderado por associações ligadas ao ensino superior e

Instituições de Ensino Superior (IES) federais, existente desde 1993,

como um dos critérios

avaliativos das

organizações

universitárias.

Complementando,

instituiu comissão de

avaliação institucional que elaborou normas e indicadores (Palharini, 2000) quantitativos $e$ qualitativos, a saber: projeto pedagógico institucional (PPI); projeto de

desenvolvimento institucional (PDI); estrutura

organizacional instâncias deliberativas órgãos acadêmicos, órgãos de apoio acadêmico, hospital universitário; ensino; pesquisa; pósgraduação; extensão; atividades artísticas, culturais e esportivas; sistemas de

comunicação; recursos humanos; suporte físico; manutenção $e$ desenvolvimento institucional. 


\section{Wh}

${ }^{3}$ Processo sistemático para avaliar produtos, serviços e métodos de trabalho de organizações reconhecidas como representantes das melhores práticas administrativas. No Ocidente, este conceito enraizou-se numa nova abordagem de planejamento estratégico e tornou-se assunto mais falado $e$ menos entendido no debate sobre qualidade. maioria das vezes, não abarca a instituição como um todo, mas se detém em nichos da organização. Inúmeros trabalhos já relatam esta caminhada. (consulte-se, por exemplo, Sguissardi, 1997). Internacionalmente são criadas redes acadêmicas e administrativas que objetivam discutir a temática da avaliação e da qualidade. Essas reúnem profissionais de avaliação e professores para trocarem experiências, como é o caso da American Association for Higher Education Assessment Forum, a Assessment Conference (Indianapolis) e a International Conference on Assessing Quality in Higher Education (Banta, 1993).

Hoje, entretanto, é registrada uma fadiga da avaliação. Dúvidas são colocadas advindas das expectativas criadas de que a avaliação seria a palavra mágica para a resolução dos problemas das instituições de educação superior. Uma questão central congrega tais dúvidas: "o que foi feito com a enorme riqueza de informações obtidas"?

Alguns autores, integrantes dessas redes de avaliação, buscando responder à questão acima, propõem uma visão micro institucional integrada a um programa de qualidade mais amplo. Eles voltam seus olhares para a quarta etapa do Ciclo da Qualidade, ou seja, a promoção desta, pela disseminação das boas práticas. É o caso de Carrol \& McConchie (1997), que analisam o avanço da qualidade por meio de exemplos - inovações, que objetivam desenvolver uma teoria de qualidade baseada na concepção de organização de aprendizagem de Senge (1992). O centro da teoria é o estabelecimento de Benchmarking ${ }^{3}$ - a melhor prática dentro das várias unidades organizacionais, que pode ser interna ou externa à organização. Os autores partem do princípio de que o coração de uma universidade é ser um criador, um repositório e um disseminador de conhecimento. Então, por que não aplicar esta filosofia para a gestão organizacional? Afirmam ainda, nesta mesma linha de pensamento, que as universidades constituem minas de ouro de boas práticas, porque estão em constante associação internacional, o que faz com que as boas práticas internas sejam construídas em práticas do mundo.

Outra questão que se coloca em relação à qualidade é a possibilidade do seu fim. Tal questão busca ser respondida, neste ano, por duas associações de marcado peso no panorama internacional, a European Association of Institutional Research, EAIR, e a Society Research of Higher Education, SRHE, por meio dos seguintes eixos: a) A avaliação externa está com seus dias contados? A burocratização do significado de qualidade aponta para a não possibilidade de flexibilização? b) o controle da qualidade foi usurpado pelo mercado e pela informação tecnológica? Será que o mercado globalizado em educação superior significa que só os melhores sobreviverão? Alguma coisa pode ser feita para controlar a qualidade na era da internet? e c) $\mathrm{O}$ desenvolvimento da educação de massa significa necessariamente o fim da qualidade? Os padrões de aquisição e de serviço podem ser mantidos num sistema de massa com o declínio de recursos?

Tais discussões levam à conclusão da necessidade da manutenção do conceito de qualidade, mas retomando-o, pois é um conceito vago e confuso. É proposto um modelo para analisar a qualidade na educação superior, a partir de três perspectivas: qualidade intrínseca; qualidade extrínseca; $e$ 
qualidade politicamente correta, em referência a três grupos importantes: a comunidade acadêmica, o mercado e o Estado. É também reafirmado o calcanhar de Aquiles da qualidade - a avaliação da aprendizagem dos estudantes e o uso de critérios de avaliação do ensino. Afirma-se ainda que a qualidade não está desaparecendo, mas transformando suas formas de avaliação. E criticam a qualidade como sinônimo de imperialismo.

\section{Qualidade, sinônimo de empregabilidade}

Nos últimos anos, alguns países da União Européia, liderados pelo Reino Unido, vêm desenvolvendo a idéia de qualidade universitária relacionada com empregabilidade.

Acompanhando esta tendência, o Centre for Research into Quality ${ }^{4}, C R Q$, tem fomentado publicações, participações e encontros sobre a temática. Seu principal pensador, Lee Harvey, afirma que, desde os anos oitenta, tem crescido a pressão sobre o sistema de educação superior visando a contribuir para a regeneração e o desenvolvimento da economia nacional. No Dearing Report isto é reafirmado: a função primária da educação superior é a preparação para o mundo do trabalho (Sguissardi, 1999). Tal pressão deságua na concepção de employability. Empregabilidade é apontada como um conceito complexo e novo. É a capacidade de os profissionais manteremse empregados ou de encontrar novo emprego quando demitidos. Minarelli (1995) entende empregabilidade como a condição de ser empregável, isto é, de dar e conseguir emprego para os seus conhecimentos, habilidades $e$ atitudes intencionalmente desenvolvidos pela educação e treinamento sintonizados com as necessidades do mercado de trabalho. Considerando o campo do ensino superior é "a probalidade do graduado apresentar atributos ${ }^{5}$ que os empregadores antecipam como necessários para o futuro funcionamento efetivo de sua organização" (Harvey, 1999, p.11).

Empregadores desejam atributos interativos e pessoais, ou seja: comunicar-se com uma ampla gama de pessoas, internas e externas à organização, relacionar-se com elas e sentir-se confortável; trabalhar efetivamente em equipe e ser capaz de reajustar seu papel de um projeto a outro. Atributos pessoais são importantes para permitir ao graduado estar dentro da cultura de trabalho, do emprego, desenvolver idéias, tomar iniciativas e responsabilidades e ajudar a política organizacional para a mudança.

Empregabilidade não é conseguir empregos para graduados. Não é nem mesmo fornecer habilidades de empregabilidade no senso mais genérico. É muito mais: desenvolvimento de capacidade crítica no processo de aprendizagem continuada. O focus necessita ser no fortalecimento de estudantes para transformarem-se em aprendizes críticos e reflexivos vencendo "formas tradicionais de ensino e prioridades de instituições de educação superior e do governo"... Enfim, é como "shift, valor tradicional que o poder da educação providencia para aqueles que participam da experiência de aprendizagem" (Harvey, 1999, p.28). O autor alerta que não é reduzir a educação superior a treinamento.
${ }^{4}$ Centro da UCE -

Universidade da Inglaterra Central, em

Birmingham, com

experiência na

elaboração de pesquisas

sobre políticas de

educação superior nos

níveis institucional,

nacional e

internacional,

informada por:

estudantes, professores, empregadores e

funcionários. Realiza

pesquisa (quantitativa

e qualitativa); revisão

de literatura e análise

de dados secundários.

\footnotetext{
${ }^{5}$ Para definir a empregabilidadeé preciso definir: O que é um emprego de graduado? Quais são seus critérios? A Associação de

Recrutamento de Graduados define como emprego de graduado qualquer emprego que o graduado ocupe. Isto reflete a diversidade de empregos de graduados e demonstra que um graduado pode exercer atividades que necessariamente não são específicas de graduados, mas nas quais ele cresce e tornase importante para a organização em que trabalha. Tal autor

baseia-se em conceitos de mudança organizacional como redução de níveis hierárquicos

(downsizing/ delaying)

$e$ flexibilidade

contratual,

caracterizando, paralelamente, o desaparecimento das carreiras tradicionais dos graduados, acompanhado da flexibilidade. Assim, a definição de empregabilidade transfere-se para atributos do graduado mais do que para as notas das disciplinas da graduação.
} 
${ }^{6} \mathrm{~A}$ auditoria de empregabilidade é baseada num relatório da instituição avaliado pelo Quality Assurance Agency (QAA), sendo proposto novo modelo de operação. As áreas cobertas são:

experiência de trabalho diversas (cursos sanduíches, projetos de vida, estágios curtos e semestrais, visitas); aperfeiçoamento (desenvolvimento de habilidades, administração de carreira etc.); desenvolvimento de habilidades profundas e explícitas em programas de estudo; reflexões sobre o que os estudantes aprenderam em atividades extraclasses. Quanto à satisfação dos estudantes, não somente informações sobre a satisfação, mas a análise de sua experiência educaciona e reflexões sobre o desenvolvimento de habilidades $e$ a apropriação das mesmas.
$\mathrm{Na}$ abertura da $15^{\text {th }}$ Biennial Conference of the International Network of Quality Assurance Agencies in Higher Education, em 1999, complementado no $15^{\circ}$ Seminar of Quality in Higher Education - "QHE 24-Hour: Employability", Harvey apresentou o indicador EPI (Employability Performance Indicator). Este tem a função de avaliar $e$ fomentar o desenvolvimento da instituição. Entretanto, os estudos apontam que mais do que alocar a ênfase na comparação de benchmarking externos faz-se importante alocar a ênfase em benchmarking internos $e$ longitudinais que permitam a comparabilidade das mudanças ocorridas. Inclusive avaliar as saídas (os graduados empregados) ao invés de input e processo (desenvolvimento de oportunidades de empregabilidade) comparando uma instituição com a outra. No tocante à análise de input e processo destacam-se a auditoria de empregabilidade e pesquisa de satisfação dos estudantes ${ }^{6}$. Nesta avaliação de empregabilidade também é incluído o indicador de saída, FDR (First Destination Returns), que deve ser coletado pelos menos até um ano da graduação, considerando as seguintes variáveis - área de conhecimento, gênero, idade, etnia, status sócioeconômico dos pais, modo de estudo (tempo integral ou tempo parcial), nível de estudo (graduado ou pós-graduado), experiência prévia de trabalho, regionalidade, qualificações de entrada, informação sobre o mercado de trabalho local e fatores macroeconômicos.

Nesta postura de qualidade que tende ao conceito de isomorfismo $e$ padronização são identificadas diversas acepções de qualidade e de tipos de padrões (adaptado de Harvey, 1995b):

Excepcional - Conceito tradicional ligado à idéia de excelência, operacionalizado na forma de padrões excepcionalmente elevados de realizações acadêmicas. A qualidade é atingida se os padrões são ultrapassados.

Perfeição ou consistência - Enfoca o processo e estabelece as especificações que busca satisfazer. Qualidade é resumida pelas idéias interrelacionadas de zero defeitos, e acertar tudo já na primeira vez.

Adequação aos fins - Julga a qualidade em termos da medida até a qual um produto ou serviço preenche sua finalidade declarada. A finalidade pode ser definida pelo aluno para satisfazer requisitos, ou definida pela instituição para refletir a missão institucional (ou objetivos do curso).

Valor em troca do dinheiro - Avalia qualidade em termos de retorno sobre investimento ou gasto. O cerne é a noção de responsabilidade. Os serviços públicos (educação) devem prestar contas aos que os financiam.

Transformação - Processo de mudança que, no ensino superior, agrega valor aos estudantes por meio de sua experiência de aprendizado. A qualidade transformativa na educação valoriza e dá poder ao consumidor.

Em relação aos padrões diferentes para a avaliação da qualidade, Harvey identifica:

Padrões Acadêmicos - Capacidade demonstrada de preencher um nível especificado de realização acadêmica. Para a pedagogia, a capacidade dos estudantes de fazerem as coisas designadas como apropriadas em determinado nível de educação. Geralmente, a competência de um indivíduo, em atingir metas e objetivos especificados (ou implícitos) do 
curso, operacionalizada via o desempenho sobre partes de trabalho avaliadas. Para a pesquisa, a capacidade de empreender estudos eficazes ou produzir novos conhecimentos, que são avaliados via reconhecimento pelos seus pares.

Padrões de Serviço - São medidas criadas para avaliar elementos identificados do serviço proporcionado em comparação com benchmarks especificados. Os elementos avaliados incluem atividades de prestadores de serviços e instalações nas quais são prestados os serviços. Os benchmarks especificados em contratos, tais como cartas de direitos dos estudantes, tendem a ser quantificados e limitados aos itens mensuráveis. As medições post hoc das opiniões dos clientes (satisfação) são usadas como indicadores da prestação de serviços.

Padrões de Competência - Demonstração de que foi alcançado um nível de habilidade sobre uma série de competências. As competências podem incluir habilidades, geralmente transferíveis, exigidas pelos empregadores: habilidades acadêmicas (de nível superior) implícitas ou explícitas no alcance de um grau de titulação ou em um aprendizado acadêmico pós-graduado; habilidades específicas congruentes com o início da prática de uma profissão.

Padrões Organizacionais - Alcance de reconhecimento formal de sistemas que assegurem a gestão efetiva de processos organizacionais e a clara disseminação de práticas organizacionais.

Aprimorando o isomorfismo, o autor propõe a relação entre Qualidade $e$ Padrões (figura 1).

A tendência ao isomorfismo na busca de padronização construiu um amplo e complexo leque de indicadores/padrões. Mas, mesmo com toda essa construção, sintetizada anteriormente, os estudiosos do assunto recomendam mais pesquisas de avaliação da avaliação, nas perspectivas de: como as agências avaliadoras mediam seu objetivos na prática; identificação de micro políticas de avaliação; análise da implementação e do impacto da avaliação; e estudos comparativos que vão desde a aprendizagem transformativa dos estudantes à desconstrução de ideologias das situações de aprendizagem.

\section{Qualidade, sinônimo de respeito às especificidades}

As categorias anteriormente identificadas - qualidade como avaliação estandardizada com tendência ao isomorfismo, acirrada no último período pela redução do conceito de qualidade à empregabilidade -, estão preferencialmente ligadas à lógica de mercado. Mas, paralelamente ao desenvolvimento desta tendência, outras surgem, trazendo também consigo indicadores de estandardização, em paralelo à preservação das especificidades.

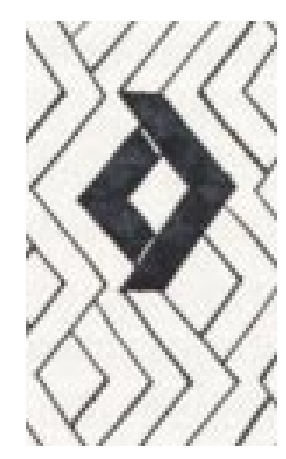
São as tendências à diversidade.

$\mathrm{Na}$ defesa desta concepção tem se destacado a UNESCO, que considera tais fatores - qualidade e diversidade, os eixos das políticas educativas. No documento "Declaração Mundial sobre Educação Superior no Século XXI: visão e ação", resultante da Conferência Mundial sobre Ensino Superior, 1998, é assim definida a qualidade em Educação Superior: 
Figura 1 - Relação entre Qualidade e Padrões

\begin{tabular}{|c|c|c|c|c|}
\hline Qualidade & $\begin{array}{l}\text { Padrões } \\
\text { Acadêmicos }\end{array}$ & $\begin{array}{l}\text { Padrões de } \\
\text { Competência }\end{array}$ & $\begin{array}{l}\text { Padrões de } \\
\text { Serviço }\end{array}$ & $\begin{array}{l}\text { Padrões } \\
\text { Organizacionais }\end{array}$ \\
\hline Excepcional & $\begin{array}{l}\text { Ênfase sobre avaliação cumulativa } \\
\text { de conhecimento e, implicitamente, } \\
\text { algumas habilidades de 'nível supe- } \\
\text { rior', padrão-ouro normativo implíci- } \\
\text { to. } \\
\text { Avaliação comparada da produção } \\
\text { de pesquisas. Elitismo: a pressupo- } \\
\text { sição de uma necessidade de man- } \\
\text { ter bolsões de alta qualidade e pa- } \\
\text { drões em um sistema de educação } \\
\text { de massas. }\end{array}$ & $\begin{array}{l}\text { Ligada à competência profissi- } \\
\text { onal; ênfase principal dada à } \\
\text { demarcação tradicional entre o } \\
\text { conhecimento e habilidades } \\
\text { (profissionais). }\end{array}$ & $\begin{array}{l}\text { Suposições impelidas por in- } \\
\text { sumos a respeito de servi- } \\
\text { ços/facilidades ligados a re- } \\
\text { cursos. Boas instalações, } \\
\text { pessoal qualificado etc. 'ga- } \\
\text { rantem' padrões de serviço. } \\
\text { Relutância em expor compe- } \\
\text { tência profissional (de ensi- } \\
\text { no) a um exame mais deta- } \\
\text { lhado. }\end{array}$ & $\begin{array}{l}\text { Hierarquia clara de papéis, } \\
\text { refletindo o status e experi- } \\
\text { ência acadêmicos. Muitas } \\
\text { vezes uma grande ênfase } \\
\text { sobre 'valores tradicionais'. } \\
\text { Grande ênfase sobre a au- } \\
\text { tonomia e liberdade acadê- } \\
\text { mica. Aversão à transparên- } \\
\text { cia. }\end{array}$ \\
\hline $\begin{array}{l}\text { Perfeição ou } \\
\text { consistência }\end{array}$ & $\begin{array}{l}\text { Destituído de significado, salvo uma } \\
\text { noção idealista de que o exame de- } \\
\text { talhado de padrões ou qualidade pe- } \\
\text { los pares será empreendido de ma- } \\
\text { neira consistente. }\end{array}$ & $\begin{array}{l}\text { Expectativa de um nível de } \\
\text { competência profissional míni- } \\
\text { mo prescrito. Problema em ava- } \\
\text { liar 'zero defeitos'. }\end{array}$ & $\begin{array}{l}\text { Relevância primária em asse- } \\
\text { gurar a qualidade de padrões } \\
\text { de serviço-sobretudo em re- } \\
\text { lação a processos adminis- } \\
\text { trativos (acurácia e confiabi- } \\
\text { lidade de registros mantidos, } \\
\text { cronogramas, trabalhos do } \\
\text { curso, medidas tomadas etc.) }\end{array}$ & $\begin{array}{l}\text { Acertou de primeira. Docu- } \\
\text { mentar procedimentos, re- } \\
\text { gulamentos e boa prática. } \\
\text { Obter certificação ISO9000. }\end{array}$ \\
\hline $\begin{array}{l}\text { Adequação à } \\
\text { finalidade }\end{array}$ & $\begin{array}{l}\text { Padrões devem ser relacionados aos } \\
\text { objetivos definidos que se relacio- } \\
\text { nam à finalidade do curso (ou insti- } \\
\text { tuição). A avaliação cumulativa deve } \\
\text { ser referenciada a critérios, embo- } \\
\text { ra, como as finalidades muitas ve- } \\
\text { zes incluem um elemento compara- } \\
\text { tivo (por exemplo, na declaração de } \\
\text { missão), esses são mediados por } \\
\text { critérios referenciados a normas. }\end{array}$ & $\begin{array}{l}\text { Especificação explícita de ca- } \\
\text { pacidades e habilidades rela- } \\
\text { cionadas a objetivos. Evidên- } \\
\text { cias necessárias para pelo } \\
\text { menos identificar padrões crí- } \\
\text { ticos. Competência profissional } \\
\text { avaliada principalmente em ter- } \\
\text { mos de mínimos críticos contra } \\
\text { exigências de entidades pro- } \\
\text { fissionais para a prática. }\end{array}$ & $\begin{array}{l}\text { A finalidade envolve forne- } \\
\text { cer um serviço. Assim, o } \\
\text { processo é avaliado em ter- } \\
\text { mos de padrões (mínimos) } \\
\text { para a finalidade - geralmen- } \\
\text { te em termos de competência } \\
\text { de ensino, o elo entre ensino } \\
\text { e pesquisa, apoio estudantil } \\
\text { (acadêmico e não acadêmi- } \\
\text { co) e assim por diante. }\end{array}$ & $\begin{array}{l}\text { Assegurar mecanismos } \\
\text { apropriados instalados para } \\
\text { avaliar se práticas e proce- } \\
\text { dimentos se adequam às fi- } \\
\text { nalidades declaradas base- } \\
\text { adas na missão. }\end{array}$ \\
\hline $\begin{array}{l}\text { Valor pelo } \\
\text { dinheiro }\end{array}$ & $\begin{array}{l}\text { Manutenção ou melhoria de desem- } \\
\text { penhos acadêmicos (padrões de } \\
\text { pós-graduação e produção de pes- } \\
\text { quisas) pela mesma unidade de re- } \\
\text { cursos. Isso deverá assegurar mai- } \\
\text { or eficiência e melhorar a experiên- } \\
\text { cia de processos dos estudantes. } \\
\text { Preocupação de que os ganhos em } \\
\text { eficiência funcionam na direção } \\
\text { oposta à melhoria de qualidade. Pro- } \\
\text { porcionar aos alunos uma experi- } \\
\text { ência acadêmica (qualificação, trei- } \\
\text { namento, desenvolvimento pesso- } \\
\text { al) que justifique o investimento. }\end{array}$ & $\begin{array}{l}\text { Manter ou melhorar a produção } \\
\text { de formandos de modo geral } \\
\text { 'empregáveis', pela mesma uni- } \\
\text { dade de recursos. Assegurar } \\
\text { um suprimento contínuo ou } \\
\text { cada vez maior de recrutas às } \\
\text { entidades profissionais pós- } \\
\text { graduadas. } \\
\text { Fornecer aos estudantes uma } \\
\text { experiência educacional que } \\
\text { aumenta a competência em re- } \\
\text { lação ao avanço na carreira, } \\
\text { que assegure um retorno so- } \\
\text { bre o investimento. }\end{array}$ & $\begin{array}{l}\text { Análises de satisfação do cli- } \\
\text { ente (estudantes, emprega- } \\
\text { dores, entidades financiado- } \\
\text { ras) para avaliar processos } \\
\text { e desfechos. Estudantes e } \\
\text { outros decisores são vistos } \\
\text { como 'clientes pagantes'. As } \\
\text { cartas de direitos dos clien- } \\
\text { tes especificam níveis de ser- } \\
\text { viço mínimos (e instalações) } \\
\text { que podem ser esperados } \\
\text { pelos estudantes (pais, em- } \\
\text { pregadores). }\end{array}$ & $\begin{array}{l}\text { Baseia-se em revisões pe- } \\
\text { riódicas ou ad hoc para sa- } \\
\text { ber se a estrutura organi- } \\
\text { zacional é efetiva e eficien- } \\
\text { te, muitas vezes informado } \\
\text { por gerentes (especialmen- } \\
\text { te estatísticas de produção } \\
\text { básica). }\end{array}$ \\
\hline Transformação & $\begin{array}{l}\text { Avaliação de estudantes em termos } \\
\text { do padrão de aquisição de conheci- } \\
\text { mento e habilidades transformativos } \\
\text { (análise, crítica, síntese, inovação) } \\
\text { contra objetivos explícitos. Enfocar } \\
\text { a agregação de valor em lugar de } \\
\text { padrões-ouro. Como a transforma- } \\
\text { ção envolve dar o poder, é neces- } \\
\text { sária uma avaliação formativa bem } \\
\text { como cumulativa. Os padrões de } \\
\text { pesquisa transformativos são ava- } \\
\text { liados em termos de impacto em re- } \\
\text { lação a objetivos. }\end{array}$ & $\begin{array}{l}\text { Proporcionar aos estudantes } \\
\text { capacidades e habilidades que } \\
\text { Ihes dêem o poder de continu- } \\
\text { ar a aprender e lidar efetiva- } \\
\text { mente com as complexidades } \\
\text { do mundo 'exterior'. } \\
\text { Avaliação dos estudantes em } \\
\text { termos de aquisição de capa- } \\
\text { cidades transformativas (aná- } \\
\text { lise, crítica, síntese, inovação) } \\
\text { e o impacto transformativo que } \\
\text { têm na fase pós-graduada. }\end{array}$ & $\begin{array}{l}\text { Ênfase dada à especificação } \\
\text { e a avaliação de padrões de } \\
\text { serviço e instalações que } \\
\text { permitem o processo de } \\
\text { aprendizado estudantil e a } \\
\text { aquisição de habilidades } \\
\text { transformadoras. }\end{array}$ & $\begin{array}{l}\text { Ênfase dada à estrutura or- } \\
\text { ganizacional que incentiva o } \\
\text { diálogo, trabalho em equipe } \\
\text { e, em última análise, dar o } \\
\text { poder ao aprendiz. Respon- } \\
\text { sabilidade delegada por } \\
\text { qualidade e padrões. Des- } \\
\text { tacam-se a inovação, res- } \\
\text { ponsividade e 'confiança'. }\end{array}$ \\
\hline
\end{tabular}

Fonte: Harvey, 1999 
é um conceito multidimensional que deve envolver todas as funções e atividades: ensino, programas acadêmicos, pesquisa $e$ fomento da ciência, ambiente acadêmico em geral. Uma autoavaliação interna e transparente e uma revisão externa com especialistas independentes, se possível com reconhecimento internacional, são vitais para assegurar a qualidade. Devem ser criadas instâncias nacionais independentes e definidas normas comparativas de qualidade, reconhecidas no plano internacional. Visando a levar em conta a diversidade e evitar a uniformidade, deve-se dar atenção aos contextos institucionais, nacionais e regionais específicos. Os protagonistas devem fazer parte integrante do processo de avaliação institucional.

(Unesco, 1998, artigo 11, alínea a)

A União Européia (UE) tem capitaneado a concepção de busca de qualidade com respeito às especificidades. Tal postura tem como pano de fundo a concepção do processo de integração entre países: muito mais pelas diferenças do que pelas similaridades. Não à imposição de um padrão único, certo, mas o fortalecimento de princípios e ações "que deram certo" e a disseminação de tais modelos para vencer os desafios de padrões insuficientes.

Entre as inúmeras estratégias para o fortalecimento das nações a serem desenvolvidas na UE podemos citar: os projetos pilotos, as recomendações sobre Qualidade na Educação Superior e o estabelecimento de uma rede de qualidade, European Quality Assurance Network - ENQA.

Em relação à primeira grande estratégia da UE - projetos pilotos, podemos citar como exemplo para desenvolver a qualidade em seus sistemas de educação superior, o de "Avaliação da qualidade do ensino escolar"7. Fundamenta-se em projeto de autoavaliação e melhoria de centros educativos realizado no marco do programa Sócrates ${ }^{8}$. Participaram neste projeto 101 centros de 18 países europeus.

Os centros gozaram de ampla liberdade para seguir um procedimento de avaliação adequado a seu contexto e estado de desenvolvimento ...compartilhavam de um núcleo comum de áreas que deviam ser avaliadas e trocavam informações sobre o processo. (Sócrates, 2001, p.10)

Objetivou-se a criação de uma rede de ajuda de especialistas de fomento à qualidade. A par das tarefas de avaliação, foram propiciados cursos de capacitação, divulgação dos resultados e discussão da idéia européia de qualidade na conferência final de Viena. Este projeto prevê sua continuidade para aqueles centros educativos que assim o desejarem, dentro do projeto Sócrates, com o fim de melhoria e de aprendizado com os outros. A concepção de qualidade é vista como respeito às especificidades.

Em relação à segunda estratégia - recomendações quanto à Qualidade na Educação Superior, a partir desses projetos pilotos, o Conselho da União Européia recomendou (24.09.1998 - 96/561/EC) que fossem estabelecidos
${ }^{7}$ Este projeto divide-se em dois subprojetos: a) diagnóstico da qualidade por meio de pautas de autoavaliação determinadas por um comitê; b) design de planos de atuação à melhoria de áreas

identificadas. O projeto contou com o apoio de um grupo assessor, que juntamente com a

Comissão Européia,

determinou o marco

conceitual e com o apoio de um grupo condutor, composto por representantes de Rennes, Insbrucke

Glasgow, responsável pelo desenvolvimento técnico. Em cada centro educativo havia um grupo assessor e um condutor; um amigo crítico; e materiais para a auto-avaliação com os questionários de coleta de informações. $\mathrm{O}$ grupo condutor era composto pelos

diversos segmentos da comunidade acadêmica $e$ tinha como função a motivação na autorevisão da organização, da gestão, do funcionamento do centro e do conjunto de atividades de ensino-aprendizagem; o amigo crítico; era uma pessoa externa ao centro educativo e com experiência de avaliação que tinha como principal função a criação de uma rede entre os centros.

${ }^{8} \mathrm{Um}$ dos principais programas educativos da União Européia no campo da Educação Superior. Integra o programa Erasmus. $\mathrm{O}$ programa Sócrates, que abrange a totalidade da área educativa, terminou sua primeira fase de cinco anos em 31 de Dezembro de 1999.

Dotado de um orçamento inicial de 850 milhões de euros, Sócrates possibilitou a mobilidade de cerca de 275.000 cidadãos europeus do mundo do ensino, tais como estudantes e professores 
universitários, diretores de estabelecimentos de ensino, professores, alunos e decisores em matéria de ensino. Por outro lado, o programa apoiou cerca de 1500 universidades, 8500 escolas e 500 projetos transnacionais para o desenvolvimento da dimensão européia e a melhoria da qualidade do ensino superior e secundário, o ensino e a aprendizagem de línguas, o ensino aberto $e$ à distância $e$ a educação de adultos. A segunda fase do programa Sócrates (2000-2006) está dotada de um orçamento de 1.850 milhões de euros.

Participam nesta fase os quinze EstadosMembros da União Européia e os países associados da Europa Central (Hungria,

República Checa,

Romênia, Chipre,

Polônia, Eslováquia, Letônia, Estônia Lituânia, Bulgária e Eslovênia) e da Europa Oriental (Turquia e Malta). Basear-se-á nas experiências adquiridas durante a primeira fase e retomará os elementos positivos do programa velando ao mesmo tempo pela melhoria e pelo agrupar de várias das ações existentes bem como por instaurar certas inovações. $O$ programa coloca a tônica sobre a educação ao longo de toda a vida, para melhorar a participação ativa $e$ a capacidade de inserção profissional.

${ }^{9}$ Adoção de um sistema fácil de comparação dos créditos; adoção de um sistema educativo baseado em dois ciclos, graduação e pósgraduação;

estabelecimento de um sistema de créditos; promoção da

mobilidade; promoção da dimensão européia na educação superior. métodos transparentes de avaliação de qualidade e sistemas de avaliação de qualidade, baseados nos princípios de: autonomia da instituição responsável pela avaliação de qualidade, respeito à autonomia da IES, vários estágios nos procedimentos de avaliação e publicação do relatório de avaliação da qualidade. Recomenda-se, também, a continuidade das medidas para o estabelecimento de um sistema permanente de avaliação da qualidade.
O suporte metodológico está baseado na conclusão de que a interpretação dos vários elementos da metodologia devem, necessariamente, estar adaptados às estruturas educacionais $e$ instituições nacionais e culturas acadêmicas nos diferentes países. Os métodos avaliativos devem refletir o contexto nos quais serão usados. (Evaluation, 2001, p.4)

Em outra citação do referido relatório, em que são analisados os diferentes focus do processo de qualidade, identifica-se o respeito à diversidade:
Em alguns países o tipo de avaliação realizada foi negociado com as instituições para satisfazer às necessidades das instituições avaliadas, i. e. Finlândia. Outros países conduzem uma atividade de avaliação com periodicidade e outros tipos de avaliação são igualmente conduzidos em atividades paralelas, Suécia. Em um pequeno número de países, as agências de avaliação têm, além das atividades de avaliação, a responsabilidade de conduzir atividades que visam melhorar a qualidade, tanto quanto solicitadas ou em cooperação com as instituições solicitantes. (Evaluation, 2001, p.10)

A Declaração de Bolonha (19.06.1999), assinada por ministros da Educação de 19 países europeus, especifica a importância da construção do espaço europeu nas suas dimensões cientifica e tecnológica, intelectual, cultural $e$ social. Estabelece uma série de recomendações ${ }^{9}$ para promover um sistema de educação superior europeu de profundidade. Entre tais recomendações é citada a promoção da cooperação européia na avaliação da qualidade com uma visão de desenvolver critérios e metodologias comparáveis. Para tal, afirma a necessidade do conhecimento dos processos de avaliação de cada país e sua validade reconhecida pelas instituições dos demais países.

Outros países componentes da União Européia têm copiado a postura de respeito às especificidades paralelamente ao desenvolvimento da qualidade. É o caso da Alemanha, que, pressionada pela junção dos seus dois Estados, desenvolveu projetos pilotos e uma estrutura organizacional coordenadora dos 16 Estados-membros e que deságua numa conexão com todo o sistema de educação superior. Além da busca de qualidade obtida pela avaliação das instituições de educação superior, que se estendem desde o processo de auto-avaliação, peers review e contrato entre a direção da IES e as chefias departamentais, incluem-se políticas de planejamento de longo prazo, alocação de recursos, reestruturação do gerenciamento, desenvolvimento organizacional, reconhecimento de programas e de instituições. Ou seja, a 
qualidade trabalha para além do nível de controle e objetiva o próprio desenvolvimento do sistema de educação superior muito mais do que a simples competitividade (HRK, 2000).

A terceira estratégia do fomento da qualidade respeitando a diversidade se concretiza na European Network for Quality Assurance in Higher Education (ENQA), estabelecida em 1999 para promover a cooperação na Europa no campo da avaliação da qualidade entre atores envolvidos no processo de avaliação. Os membros da rede são agências de avaliação de qualidade, autoridades públicas responsáveis pela educação superior e associações de instituições de educação superior dos Estados-membros da União Européia Os principais serviços e benefícios oferecidos pela ENQA relacionam-se a informações sobre o desenvolvimento recente na avaliação da educação superior e acesso a workshops e treinamento de recursos humanos, bem como a participação em atividades temáticas e projetos especiais.

Qualidade, sinônimo de eqüidade

Paralelamente às discussões e estratégias que vêm ocorrendo nos países do norte da União Européia, quanto à qualidade como tendência ao isomorfismo ou à diversidade, outra corrente, de menor porte, desponta no panorama europeu. É aquela que considera qualidade como sinônimo de eqüidade.

O Institut Nacional de Calidad y Evaluación (INCE), do Ministério de Educação, Cultura e Desporto, publica um número específico de seu periódico - Revista de Educación, sobre a temática Equidad y Calidad en Educación. Nesses estudos duas idéias prévias são defendidas: qualidade e eqüidade são conceitos inseparáveis; e a comunidade educativa é responsável pela aplicabilidade e o êxito ou fracasso de políticas educativas de qualidade com eqüidade. São citados nove fatores-chave para a busca da qualidade com eqüidade: extensão da educação, tratamento da diversidade, autonomia escolar, currículo/autonomia curricular, participação da comunidade educativa e gestão dos centros, direção escolar, professorado, avaliação $e$ inovação e investigação educativas. Ressalta-se que a qualidade está para além da simples padronização de indicadores, abarcando estudos qualitativos $e$ quantitativos.

Como modelo econômico fundante da postura vigente na concepção de qualidade, é apontada a redefinição do papel do Estado e a revalorização da ideologia do mercado com a proposição do neoliberalismo educativo mitigado (Afonso apud INCE, 1999). Decorrente desta análise são relatadas experiências educativas com meninos desfavorecidos, com pessoas portadoras de desigualdades decorrentes de diferenças de sexo, situação sócio-econômica e étnica (por exemplo, os ciganos). São incluídos estudos com docentes de licenciatura, com gestores de instituições e com disciplinas curriculares.

A postura de qualidade como eqüidade também é defendida pela UNESCO. Na Reunião do Comitê Regional Intergovernamental do Projeto Principal de Educação na América Latina e Caribe (PROMEDLAC VII), realizada em 08 de março de 2001, os Ministros de Educação concluíram pela adoção da Declaração de Cochabamba ${ }^{10}$, dando seguimento ao Foro Mundial sobre a Educação (Dakar ${ }^{11}$, abril, 2000).
${ }^{10}$ As 54 recomendações da Conferência articulam-se ao redor de nove pontos básicos: os novos sentidos da educação num mundo globalizado e em permanente mudança; as aprendizagens de qualidade e atenção à diversidade como eixos prioritários das políticas educativas; o fortalecimento e a resignificação do papel dos docentes; os processos de gestão a serviço das aprendizagens e da participação; a ampliação e

diversificação das oportunidades de aprendizagem ao longo da vida; a apropriação de meios e tecnologias para a transformação

da educação; o

financiamento; os sistemas de informação para o melhoramento das políticas e práticas educativas; $e$ a cooperação internacional. Estas recomendações figuram como complementares aos Marcos de Ação adotados no Foro Mundial sobre Educação e na Reunião Regional Preparatória (Santo Domingo, fevereiro de 2000). 
${ }^{11} A$ comunidade internacional sabe que as razões para assegurar um acesso universal e uma educação de qualidade são imperativas. $A$ educação contribui para o bem estar econômico e para a coesão, assim como para a estabilidade das comunidades e oferece aos pobres os meios para aumentar seus ingressos e liberarse da pobreza. Nenhum país conseguiu jamais assegurar um crescimento econômico duradouro sem alcançar o crítico umbral da alfabetização de sua população.

Igualmente, a

educação transforma vidas oferecendo oportunidades eqüitativas de escolarização para as meninas, pela estreita relação entre seu nível de educação e as eleições que estas farão mais tarde durante suas vidas: trata-se do número de filhos que terão, a sua taxa de sobrevivência, o seu rendimento escolar; seu futuro profissional, todos elementos que influem diretamente sobre o crescimento

econômico nacional. (Unesco, 2001, p.2)
Fica clara a posição de qualidade como eqüidade.

O uso pedagógico das tecnologias de informação e comunicação deve ocorrer no marco de um projeto social e educativo comprometido com a eqüidade e com a qualidade. ... não podemos esquecer que a opção por tornar mais eficientes estas aprendizagens deve considerar mais as potencialidades do que as pessoas - e muito particularmente os professores - e o respeito às identidades culturais, antes que as próprias promessas da tecnologia. (Foro Mundial, 2000, p.4)

\section{Qualidade universitária, desafios e dúvidas}

O Estado avaliador marcou o final do século passado e continua marcando o início deste. As tendências internacionais, trazidas pela idade do conhecimento, acirradas pela internacionalização e pelo desenvolvimento $e$ disseminação de acesso às novas tecnologias de informação, têm diminuído o fosso de adoção de medidas educativas, entre o norte e o sul, entre os países que têm altos índices de população na universidade e aqueles em que, praticamente, só uma minoria tem acesso ao ensino superior. Vivemos a era da qualidade, num país caracterizado historicamente pelo controle do Estado sobre a Educação Superior. No afã de sermos modernos e integrantes do concerto mundial aceitamos cartilhas que orientam os países subdesenvolvidos a reduzirem o papel do Estado na educação superior $e$ copiamos políticas educativas de outras realidades paralelamente ao alijamento de construções próprias. Muitas vezes, essas mesmas cartilhas reconhecem os erros da minimização da importância da formação de recursos de alto nível e da produção de conhecimento local.

Assim, entre as tendências da qualidade como isomorfismo e respeito à diversidade, nós, os latino-americanos, não podemos nos esquecer do conceito de qualidade para a preservação da cidadania. Não podemos nos esquecer de que somente $4 \%$ da população têm o ensino superior completo e 12,2\% o médio. Muitas vezes, copiando tendências internacionais, ipsis litere, reforçamos a estratificação vigente, na qual, de um lado, estas instituições universitárias e/ou nichos em condições iguais ou muito similares a instituições internacionais de excelência $e$, de outro, um ensino superior rarefeito, com poucos programas de pós-graduação reconhecidos pelos órgãos governamentais e professores com índices de qualificação baixos.

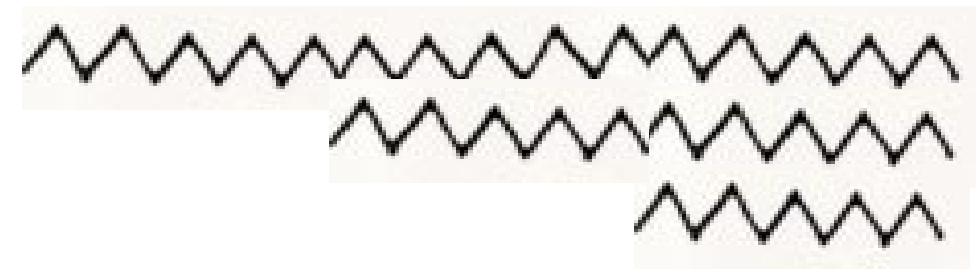


A questão que fica, a partir do mapeamento realizado neste texto, e que transfiro aos meus leitores é: Qualidade garante inovação na educação superior? Se sim: qual é o conceito de qualidade? E ainda: existe excludência entre os conceitos apresentados?

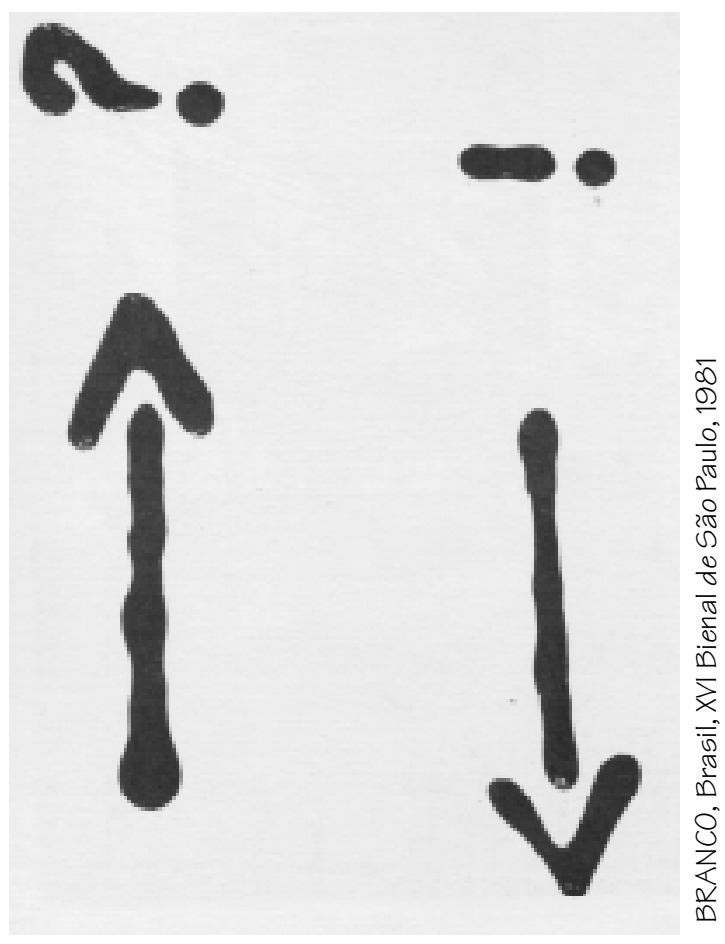

Referências bibliográficas

ANPED. Associação Nacional de Pós-Graduação e Pesquisa em Educação. Universitas: a produção científica sobre educação superior no Brasil: 1968-2000. GT de Educação Superior. Caxambu, 2001.

BANTA, T., ASSOCIATES (Orgs.) Making a difference: outcomes of a decade of assessment in higher education. San Francisco: Jossey-Bass, 1993.

CARROL, M., MCCONCHIE, A. Avanço da qualidade através de exemplos: desenvolvendo uma teoria para construir uma organização de aprendizagem através de exemplos. In: NINTH INTERNATIONAL CONFERENCE ON ASSESSING QUALITY IN HIGHER EDUCATION, Indianapolis, 1997. (mimeogr).

EVALUATION OF EUROPEAN HIGHER EDUCATION: A Status Report. Denmark, 1998. Disponível em: <www.enqa.net/docs.lasso/statusreport1.html>. acesso em: 20.abr.2001.

FORO MUNDIAL SOBRE EDUCAÇÃO. Santo Domingo, fevereiro de 2000.

HARVEY, L. Evaluating the evaluators. Centre for Research into Higher Education. Santiago, 1999. Disponível em: <www.uce.uk/crq/publicatios/cp/chile99>. acesso em: 24.abr.01. 
HARVEY, L. New Realities: the relationship between higher education and employment. European Association of Institutional Research. Lund: august, 1999. Disponível em: <www.uce.ac.crq/ publications/cp/eair99>. acesso em: 19.abr.01.

HRK. Hochschul Rektoren Konferenz. Quality Assurance in German Higher Education.

National Report. Berlin: European Association of Higher Education, 2000. (Conference)

INCE. Equidad y calidad en educación. Rev. Educ., n.319, p.135-53,1999.

INCE. Comision Europea. Evaluación de la calidad en la enseñanza escolar: Proyecto Piloto Europeo. Madrid: Ministerio de Educación y Cultura/INCE,1999.

MINARELLI, J. Empregabilidade: o caminho das pedras. São Paulo: Gente, 1995.

PALHARINI, F. PAIUB 2000 - Matriz geral do processo de avaliação institucional. Brasília: Comitê Assessor PAIUB, 8, 11, 2000. (mimeogr).

SENGE, P. M. The fifth discipline: the art and the practice of the learning organization. Sidney:

Random House, 1992.

SGUISSARDI, V. (Org.) Avaliação universitária em questão: reformas do Estado e da

Educação Superior. Campinas: Autores Associados, 1997.

SGUISSARDI, V. O Dearing Report - Serão as mudanças na educação britânica "modelo" para o

Brasil? CIPEDES, n.4, set., p.15-27. (Separata de Avaliação/RAIES, v.4, n.3, 1999).

SÓCRATES. ERASMUS. The European community Programme in the field of higher education.

Disponível em:<www. europa.eu.int/comm/education/socrates/erasmus/recom.html>. acesso em: 20.abr.01.

UNESCO. DECLARAÇÃO MUNDIAL SOBRE EDUCAÇÃO SUPERIOR NO SÉCULO XXI: visão e ação. Conferência Mundial sobre Ensino Superior, 1998.

UNESCO. Los países de América Latina y el Caribe adoptan la declaración de

Cochabamba sobre Educación. Bolívia: Oficina de Información Pública para América Latina y el Caribe, 2001 (Presse n. 2001-35)

VAN VUGHT, F. Towards a general model of quality assurance in Higher Education. In: BRENNAN,

VAN VUGHT, F. (Eds.) Questions of quality: in Europe and Beyond. London: Quality Support Center, 1993.

MOROSINI, M. C. Calidad del educación universitaria: isomorfismo, diversidad y equidad, Interface - Comunic, Saúde, Educ, v.5, n.9, p.89-102, 2001.

Las tendencias internacionales surgidas en la edad del conocimiento, incrementadas por la internacionalización y por el desarrollo de nuevas tecnologías de comunicación, han diseminado, marcadamente, entre nosotros -país históricamente caracterizado por el control del Estado sobre la educación superior-, la era de la calidad. Este trabajo examina diferentes concepciones y estrategias de calidad universitaria, derivadas de experiencias internacionales. Entre los principales conceptos se destacan el de calidad, sinónimo de isomorfismo, reflejándose como evaluación institucional estandarizada y empleabilidad; calidad, sinónimo de respeto a las especificidades; y calidad, sinónimo de equidad. Por la escasez de bibliografía en relación a una visión holística del tema, este trabajo, mas que conclusiones definitivas, plantea cuestionamientos respecto a la relación entre calidad e innovación educativa y unicidad del concepto de calidad y realidad brasileña.

PALABRAS CLAVE: Calidad; innovación organizacional; universidad; evaluación institucional, educación superior. 

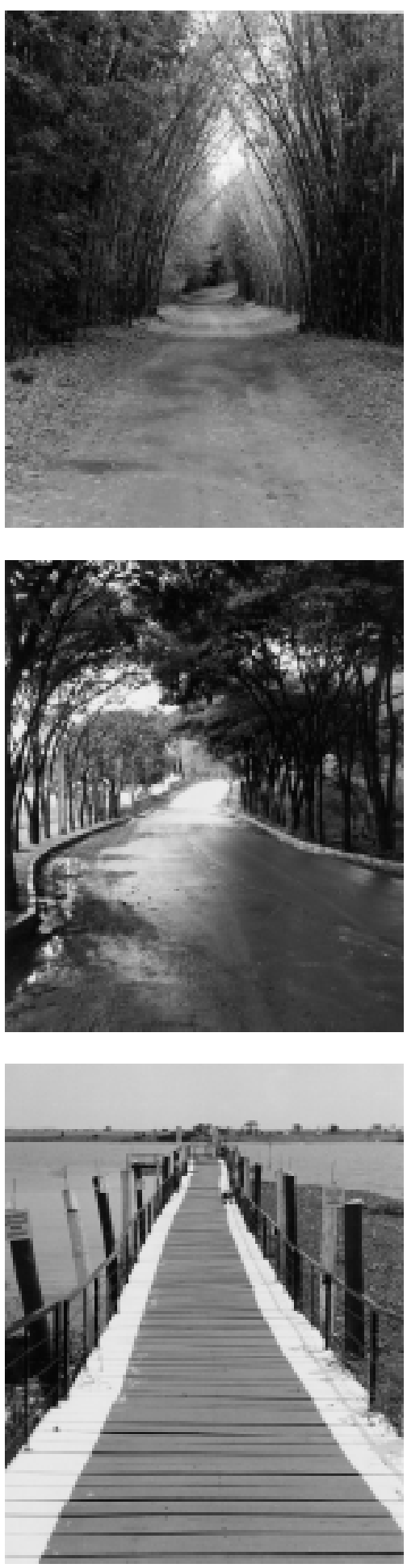

MARIA DO SOCORRO, Botucatu, 2001

102 Interface-Comunic, Saúde, Educ 9 